\title{
New energy sources for catheter ablation
}

Paul Wang, Munther Homoud, Mark Link, N. A. Mark Estes

Paul J. Wang M.D., Munther K. Homoud M.D., Mark S. Link M.D., N. A. Mark Estes M.D., "New energy sources for catheter ablation," Proc. SPIE 10297, Matching the Energy Source to the Clinical Need: A Critical Review, 102970A (24 January 2000); doi: 10.1117/12.375230

SPIE. Event: Digital Optical Computing, 1990, Los Angeles, United States 


\title{
New Energy Sources for Catheter Ablation
}

\author{
Paul J. Wang, MD \\ Munther K. Homoud, MD \\ Mark S. Link, MD \\ N. A. Mark Estes III, MD \\ Cardiac Arrhythmia Service \\ Box 173, 750 Washington Street \\ New England Medical Center \\ Tufts University School of Medicine \\ Boston, MA 02111
}

[617] 636-5902

FAX [617] 636-4586

\section{INTRODUCTION}

Catheter-based techniques have been used successfully in the treatment of many patients with various cardiac rhythm problems, including A-V nodal reentrant tachycardia, accessory pathways, and other atrial and ventricular arrhythmias. These techniques have had limited success in the treatment of disorders such as ventricular tachycardia in the setting of prior myocardial infarction. New techniques are needed to create the larger lesions required for treatment of such conditions. In addition, conditions such as atrial fibrillation and atrial flutter require new catheter-based techniques for linear ablation. As a result, a wide range of energy sources have been investigated and developed.

\section{MODIFIED RADIOFREQUENCY ABLATION}

Radiofrequency ablation has been the primary energy source for thousands of catheterbased treatments of cardiac arrhythmias. Radiofrequency energy results in the resistive heating of myocardial tissue. Since radiofrequency lesions are typically 1 to $3 \mathrm{~mm}$ in diameter, methods of modifying radiofrequency ablation have been developed.

The cooling of the electrode-myocardial interface has been a fundamental modification, permitting the delivery of much higher energy levels. The larger lesions have been used clinically for the treatment of ventricular tachycardia in the setting of coronary artery disease and atrial flutter.

Other modifications of radiofrequency ablation have been made predominantly to increase lesion size. Largerpp广c. CCC code: $0277-786 \mathrm{X} / 17 / \$ 18 \cdot$ doi: $10.1117 / 12.375230$ 
area of contact. In addition, the use of panel electrodes or arrays has been used to increase the current density or change the surface area in contact with the myocardium. $1,3-5,8-12,14-16$

\section{CRYOABLATION}

Cryothermia has been used to treat a large number of medical conditions, including prostatic hypertrophy, dermatologic growths, and ophthalmologic disorders. Cryothermia has been shown to result in the destruction of myocardial tissue and therefore has been applied to the treatment of various cardiac arrhythmias. Developed initially as a surgical method, cryoablation is undergoing resurgence, now as a potential catheter-based technique.

Cryoablation results in the freezing of myocardium tissue, leading to cell death. There are a number of reported ultrastructural changes due to freezing. Damage may occur to the mitochondrial membrane, resulting in irreversible impairment of mitochondrial function. Myofibril structure becomes disturbed and ice crystal formation may result in damage to cytoplasmic elements and impairment of membrane function.

Cryothermia results in formation of a frozen region of myocardial tissue, often appearing to be an ice ball. Irreversible changes in the myocardium occur when the temperature is dropped to the range of -30 degrees to -70 degrees $C$. After the initial freezing phase, there is evidence of hemorrhage and edema. Polymorphonuclear cells and other inflammatory cells enter the disturbed region. Over time, the region is replaced with a fibrous tissue. This process begins 2 weeks after the initial injury.

\section{Electrophysiologic Effects of Cryothermia}

Acutely, the application of cryothermia to the myocardium results in a reduction of the amplitude of electrograms at or near the site of ablation. These electrophysiologic abnormalities persist over time, following the development of cryoablation scar. The dense region of fibrosis produced by the ablation is devoid of significant electrical activity

Acutely premature ventricular beats are observed, possibly resulting from enhanced automaticity. Ventricular ectopy disappears by 1 week. ${ }^{18}$ Programmed stimulation has not demonstrated inducible arrhythmias. This experimental data is in agreement with clinical observations of the absence of significant proarrhythmia due to cryoablation. The well-demarcated lesions may account for the absence of proarrhythmia.

\section{Cryothermal mapping}

A unique characteristic of cryothermal techniques is the ability to alter reversibly the electrophysiologic properties of myocardial tissue. ${ }^{19-21}$ Cooling myocardial tissue results in a decrease in amplitude of local electrogram signals and an increase in refractory 
periods. Sterile ice cubes have been applied both experimentally and clinically to locate the site of origin of an arrhythmia. A cooling source at 0 degrees decreased the surface temperature by $-18 \pm 3.1$ degrees $C$ at $0 \mathrm{~mm}$, and $-4.2 \pm 2.3$ degrees $\mathrm{C}$ at $2-3 \mathrm{~mm}$ subepicardially, and $-1.3 \pm 1.3$ degrees $C$ at 5 to $7 \mathrm{~mm}$ depths. ${ }^{20}$ Frequently the site at which cooling terminated the tachycardia was located 3.0 to $7.5 \mathrm{~cm}$ from the site of earliest electrical recording. ${ }^{19} 21$ It is possible to use a cryoablation catheter to alter the properties of the myocardial tissue reversibly. ${ }^{19}$ However, such techniques may only be applicable to sites that are relatively superficial.

\section{Cryoablation Designs and Systems}

Cryoablation systems were originally developed for surgical use. These systems utilized the Joule-Thompson effect and employed gaseous nitrous oxide. Nitrous oxide was stored in a tank off the surgical field and regulated using a control console. This console was connected to a large diameter supply tube that was sterilized and connected to a hand-held cryosurgical probe. Within this probe, the nitrous oxide was delivered to a nozzle at which the nitrous oxide expanded and decreased pressure. This change in pressure resulted in a significant decrease in temperature. The cryosurgical probe may have one of several configurations, usually with a circular "foot-print".

Surgical probes are designed to achieve maximum cooling reliably with the ability to control the amount of cooling. The supply tube can be large and the probes may be reusable. In contrast, there are important constraints that catheter-based systems have. These tube-like structures must be small enough in diameter to pass easily through the venous or arterial system. Usually, these tubes are less than $3 \mathrm{~mm}$ in diameter. The tubes must be flexible and strong. They also must maintain their shape and the ability to be manipulated or steered to the correct location within the vascular system and within the heart. In addition, the catheters must be able withstand internal pressures and temperatures that may be created by the cryothermal techniques. An extremely important safety consideration is the potential life-threatening risk if nitrous oxide or other agents leaked into the blood stream.

While cryosurgical systems are commercially available, catheter cryoablation systems have only been developed experimentally or in early clinical studies. There are several potential designs employed in catheter-based systems. Some catheter-based systems are based on the Joule-Thompson principle and utilize nitrous oxide ${ }^{22}$. These systems are quite similar to the surgical cryoablation systems. They operate at approximately 500 to $800 \mathrm{psi}$ and achieve temperatures from -50 to -80 degrees $\mathrm{C}$.

Another system utilizes a phase change from liquid to gas, resulting in freezing. ${ }^{17,19}$ Delivery of a liquid has the potential advantage of necessitating much lower pressures within the catheter tubing. This system and that utilizing the Joule-Thompson effect have the advantage that the cooling occurs at the distal end of the catheter, rather than requiring cooled fluid to be delivered to the catheter. Delivery of liquid refrigerants such as liquid nitrogen has been used experimentally but has the disadvantage of requiring 
insulation materials to maintain the temperature of the liquid throughout the approximately 1 meter length of the catheter.

Experimentally, semiconductors may be used to achieve a temperature differential via the Peltier effect. By creating a temperature differential, the heat is removed from the tissue and deposited on the other side. In multiple steps or stages, significant cooling may be achieved.

\section{Determinants of Lesion Size}

The size of cryoablative lesions is affected by the temperature achieved and the duration of the lesion. Lesion size increases with the total duration up to approximately 5 minutes at which time the lesion size plateaus. ${ }^{23}$ Circulation of blood also greatly affects the size of the cryoablative lesion since the blood warms the tissue being ablated. ${ }^{24}$ Repetitive freezing and thawing may also increase lesion size. Repeated freezing of myocardial tissue that is already below body temperature also results in an increase in lesion size. ${ }^{23}$ The size of the probe also determines the lesion size. The increased surface area of the probe will increase the surface area of the lesion and the depth.

\section{Clinical Applications of Cryoablation}

\section{A-V Junction}

Surgical cryoablation has been used to create A-V block. ${ }^{25,26}$ Most of these procedures have been with the right atrium opened while the patients are on cardiopulmonary bypass. Therefore, the warming effects of the blood during the cryoablation lesions were not present.

Percutaneous cryoablation techniques for A-V junction ablation have been performed experimentally and in initial clinical studies. $17,19,22,27$

create persistent A-V block in 5 out of 8 animals. These ablative lesions were small and well-circumscribed. Using an 8 Fr steerable halocarbon cryoablation catheter, reversible and irreversible block in the AV junction has also been demonstrated. Reversible PR prolongation and 2:1 AV block occurred at -20 to -50 degree $\mathrm{C}$ without histologic damage to the AV node. Complete irreversible block is also feasible using this catheter.

Cryoablation has also been applied to modification of A-V nodal function. Holman et al demonstrated that cryoablative surgical lesions encircling the triangle of Koch resulted in modification of $A-V$ nodal properties with acute prolongation of $A-V$ nodal refractory periods. ${ }^{28}$ Drug refractory A-V nodal reentrant tachycardia has been treated with this technique.

\section{Accessory Pathway}

Cryoablation has been applied extensively surgically. Cryothermal mapping has been used surgically to demonstrate reversible block across the accessory pathway. 
Cryoablation has been applied endocardially or epicardially in these surgical procedures. A special probe has been developed for ablation with in the coronary sinus to treat left sided accessory pathways. ${ }^{29}$ Experimentally cryoablation may be performed under the mitral annulus, suggesting that this technique may be used to treat left-sided accessory pathway cryoablation via a retrograde approach. ${ }^{30}$

\section{Ventricular Tachycardia}

There has been extensive experience with the ablation of ventricular tachycardias using cryoablation. In some cases these have been in conjunction with other procedures such as endocardial resection. Cryoablation alone has been used to treat patients with ventricular tachycardia in the setting of coronary artery disease. Myocardial lesions in the right and left ventricle have been created using a catheter-based cryoablation system. ${ }^{17}$ Lesions with a median volume of $39 \mathrm{~mm}^{3}$ were created using serial applications of temperatures of $-18 \mathrm{C}$ to -60 degrees $\mathrm{C}$ for up to 4 minutes.

\section{Atrial Fibrillation}

Using the maze procedure, a series of incisions and cryoablations have been used to treat atrial fibrillation effectively. Cryoablation using a $5 \mathrm{~cm}$ tip has been compared to radiofrequency ablation using a ten $5 \mathrm{~mm}$ rings with $2 \mathrm{~mm}$ interelectrode. Thrombus was only minimal with cryoablation compared to extensive mural thrombus during radiofrequency ablation.

\section{LASER ABLATION}

The acronym laser stands for Light Amplification by Stimulated Emission of Radiation. A variety of materials may be stimulated, creating a monochromatic phase-coherent beam. A wide range of frequencies may be used: $250 \mathrm{~nm}$ to $10600 \mathrm{~nm} .^{33-4 l, 42-59}$ Lasers may use gases such as helium-neon $(633 \mathrm{~nm})$, argon $(488 \mathrm{~nm}$ and $515 \mathrm{~nm})$, holmium $(2100 \mathrm{~nm})$ and carbon dioxide or use employ substances such as ruby $(693 \mathrm{~nm})$ or neodymium- yttrium-aluminum-garnet (Nd:YAG, $1064 \mathrm{~nm}$ ).

Laser techniques have been used extensively in ophthalmology, dermatology, and cardiology. Lasers have been introduced for myocardial ablation. ${ }^{33,34,36,53-58}$ Variables important in determining the effects of the laser include the laser type, its duration, energy density, and the properties of the tissue.

Laser energy may be absorbed by myocardial tissue resulting in vaporization and cutting. $\mathrm{CO} 2$ lasers, for example, primarily result in absorption with very little penetration. ${ }^{48,51}$ Lasers in the infrared region such as Nd:YAG YAG (neodymiumyttrium-aluminum-garnet) result in the scattering of the photons before they are absorbed. This results in photocoagulation caused by the distribution of energy at a greater depth. 
Ultraviolet radiation Xenon fluoride excimer, which produces energy in the ultraviolet range, results vaporization of tissue in a thin layer.

The laser frequency determines the balance between scattering and absorption. As the power density and duration increase, the lesion depth increases. As the irradiating spot size increases, the size and depth of the lesion increase. ${ }^{48}$ The nature of the region that is targeted will determine the selection of the type of laser. A-V junction modification will require a relatively superficial lesion while ventricular tachycardia may require deeper penetration. Argon lasers are used for superficial structures. The Nd:YAG lasers may be used for deep structures such as ventricular tachycardia.

\section{Catheter Design Characteristics and Requirements}

Catheter-based laser devices require the efficient delivery of energy without significant absorption by the fiber optic cable. Nd:YAG and Argon may be transmitted without significant loss in the optical fiber, which are typically 200 and 600 um in diameter. The energy must be effectively coupled to the myocardial tissue so that the energy is not dissipated in the circulating blood. Saline may be flushed continuously at the end of the catheter, removing blood from the path of the laser beam. A saline-filled balloon may also be used to push blood away from the endocardial surface. This system may be adapted to using an endoscope within a transparent balloon at the distal end of the catheter. Hirao et al performed selective A-V junction or slow pathway using this approach.

Laser energy must be delivered relatively perpendicular to the endocardial surface in order to maximize transmission of energy. Mechanical prongs or suction at the end of the catheter may be used to stabilize the catheter in a perpendicular position. The laser beam also may be delivered from the side of a catheter lying alongside the endocardium.

A considerable amount of heat may be generated at the myocardial interface. Some catheter-based designs employ saline cooling to reduce the temperature. tissue compared to normal ventricular tissue. Pulsing of laser energy at low repetition rates may also be used to decrease the peak temperature at the ablation site.

\section{Pathologic and Electrophysiologic Effects of Laser Energy}

Laser energy acutely results in crater formation, coagulation necrosis, and vacuolization There may be a central vaporized crater surrounded by a rim of necrotic tissue. Water-soluble gaseous substances may be released. These byproducts are small in the range of 3 um in size. Acutely, laser energy may result in perforation of tissue. Over time, a homogenous region of fibrosis replaces laser ablative lesions.

Laser energy reduces the resting membrane potential, action potential amplitude and upstroke velocity. These effects extend several millimeters beyond the edge of the region of necrotic myocardium. 


\section{Clinical Applications}

\section{A-V Junction}

A $7 \mathrm{Fr}$ catheter was used to deliver energy from an argon laser to achieve complete transection of the AV junction. ${ }^{43}$ A Nd:YAG laser has been effective in the treatment of A-V nodal reentry and creation of A-V block. ${ }^{49,55,57}$ Transvenous laser ablation of the A-V junction has also been accomplished using endoscopic techniques. ${ }^{44}$ A laser-based thermal ablation catheter has also been tested for $\mathrm{A}-\mathrm{V}$ junction ablation.

\section{Ablation of Accessory Pathways and the Atrium}

There is only limited experience with the use of lasers for atrial and supraventricular arrhythmias other than A-V nodal reentry. Laser ablation has been used only selectively for atrial flutter, for example. ${ }_{56}^{54}$ Weber et al have demonstrated the feasibility of laser ablation of atrial myocardium. ${ }^{56}$ Laser ablation has been used in left-sided accessory pathways. $^{41}$ A laser-based balloon catheter has been tested for use via the coronary.

\section{Ventricular Tachycardia}

Laser ablation offers particular advantages for the treatment of ventricular tachycardia. Laser energy is capable of creating lesions larger than possible with conventional radiofrequency energy. ${ }^{58}$ Laser energy created lesions with a mean volume of $996 \pm 73$ $\mathrm{mm}^{3}$ versus $111 \pm 38 \mathrm{~mm}^{3}$ for radiofrequency ablation. ${ }^{58}$ Intraoperatively laser ablation has been extensively used to treat ventricular tachycardia. Laser has been applied both endocardially and epicardially. ${ }^{46}$ The irradiation surface area required for ventricular tachycardia termination may range from 2.3 to $9.4 \mathrm{~cm}^{2}$ in cases where the ventricular tachycardia is well-mapped to 9 to $19.5 \mathrm{~cm}^{2}$ in less well defined ventricular tachycardias [Svenson, $1990 \# 20$ ]. Laser ablation has been predominantly in patients with ventricular tachycardia in the setting of prior myocardial infarction.

In summary, laser ablation has been used successfully but catheter-based techniques are in the early stages of investigation are not commercially available.

\section{MICROWAVE ABLATION}

Microwave energy has been used for numerous commercial and household applications. In the medical field, microwave energy has been used for the treatment of neoplasms and prostatic hypertrophy. In addition it has been used for sterilization as well as blood and fluid warming. 


\section{Principles of Microwave Ablation and Microwave Systems}

Microwave ablation acts via dielectric heating of the myocardium. ${ }^{60-79}$ Microwave heating occurs due molecular motion of water molecule dipoles in myocardial tissue. The microwave systems consist of a microwave generator, which serves as the energy source, and an antenna, which radiates electromagnetic energy. The design of the microwave antenna determines the geometry of the electromagnetic field. A helical coil design consists of a helical coil attached to the inner conductor extending beyond the coaxial cable. A monopolar or whip antenna is another antenna design.

The generator most commonly uses either $915 \mathrm{MHz}$ or $2450 \mathrm{MHz}$ frequencies. The Federal Communications Commission approves these frequencies for medical use. The frequency $915 \mathrm{MHz}$ may result in deeper penetration depending upon the antenna characteristics and efficiency. The lower the frequency the lower amount of loss in the coaxial cable, decreasing the heating of the cable.

Because the nature of the ablative lesion depends upon the electromagnetic field properties, it is possible to evaluate each antenna by measuring its heating characteristics. Utilizing a phantom material having dielectric properties similar to myocardial tissue, several measurements may be made to describe the microwave antenna at a specific frequency. A systems analyzer delivers energy over a large range of frequencies and measures the amount of energy that is deposited into the tissue. Some of the energy is reflected back to the generator and is not delivered to the tissue or phantom. When the antenna is well suited or "matched" to the tissue, almost of the energy is delivered to the tissue.

Another measure of the antenna's electromagnetic properties is the specific absorption rate (SAR). Energy is delivered and the instantaneous temperature generated at each point in space is measured. The three-dimensional temperature distribution is used as a description of the relative microwave energy field strengths.

The microwave heating pattern varies by the antenna configuration. A helical coil creates a circumferential heating pattern, ideal for positioning parallel to the endocardial surface. Helical coil antennas may be used to make linear lesions such as for atrial fibrillation ablation. Some dipole antennas may project the ablation energy forward.

\section{Comparision of Microwave Ablation and Radiofrequency Ablation}

There is evidence that microwave energy may lead to deeper lesions compared to radiofrequency energy. In vitro phantom studies demonstrated that temperatures increased at a greater depth during microwave ablation compared to radiofrequency energy. Studies in an isolated perfused porcine right ventricular tissue model demonstrated that lower antenna-tissue interface temperatures achieved comparable depths of lesions: $70.4 \pm 13.5^{\circ} \mathrm{C}$ and $83.6 \pm 7.9^{\circ} \mathrm{C}$ for microwave and radiofrequency 
lesions, respectively $(\mathrm{p}=0.004) .^{77} \mathrm{~A}$ split tip microwave antenna at 30 Watts for 20 seconds had a lesion depth of $3.8 \pm 0.7 \mathrm{~mm}$ and $2.6 \pm 0.7 \mathrm{~mm}$ for microwave and radiofrequency lesions in an excised bovine heart model $(\mathrm{p}<0.0001)$. ${ }^{67}$ Such comparisons of microwave ablation with radiofrequency are highly dependent upon the characteristics of the antenna used. ${ }^{76}$ In a study comparing a helical antenna to radiofrequency ablation, ventricular lesions were longer using microwave ablation but the lesion depth and width tended to be greater with radiofrequency ablation. ${ }^{80}$ Therefore, at present, additional data using different antennas are needed to demonstrate that microwave ablation is capable in vivo of larger lesion size.

\section{Clinical Applications}

\section{A-V Junction}

A helical antenna ablation catheter has been used to create chronic A-V block using microwave energy at $2,450 \mathrm{MHz}$. Lesions were $4.7 \pm 2.1 \mathrm{~mm}$ in length, $2.8 \pm 1.3 \mathrm{~mm}$ in width, and $0.9 \pm 0.25 \mathrm{~mm}$ in depth. The mean escape rate was $44 \pm 10$ beats per minute at 6 weeks. Other studies have also demonstrated the ability to perform A-V junction ablation using a microwave ablation system. ${ }^{79}$ Subsequent studies have demonstrated that A-V block may also be created with a forward-firing double helix antenna.

\section{Ventricular Arrhythmias}

Microwave ablation systems that may be able to create lesions with a larger surface area, depth, and volume, which might be effective in the treatment of many ventricular tachycardias. There are several factors that affect ventricular lesion size. As the power and duration of microwave energy delivery are increased, the lesion size also increases." Caution must be taken, however, to avoid excessive temperatures resulting in thrombus formation. ${ }^{74}$ Because microwave energy may be delivered despite tissue coagulation, temperature monitoring during microwave ablation is particularly important. A feedback control microwave ablation system may be used to achieve a selected target temperature.

\section{Atrial Arrhythmias and Atrial Fibrillation}

Microwave energy has been used to successfully ablated aconitine-induced experimental atrial tachycardia. $\quad$ A variety of linear ablation devices have been designed for catheterbased maze procedures. Intraoperative endocardial linear ablation has been performed in 18 patients with chronic atrial fibrillation and concomitant surgery for coronary artery bypass graft surgery and mitral valve surgery. Only three patients had atrial fibrillation at 30 days of follow-up. 
In summary, microwave ablation may be a promising technique, potentially capable of treatment a wide range of ventricular and supraventricular arrhythmias.

\section{ULTRASOUND ABLATION}

Ultrasound energy results from the vibration of a piezoelectric crystal when an electrical current is applied ${ }^{83,85}$ Ultrasound ablation occurs from the disruption of cell membranes and tissue heating. Experimental studies using frequencies from $4.5 \mathrm{MHz}$ to $10 \mathrm{MHz}$ have demonstrated a depth of up to $8 \mathrm{~mm}$ in the left ventricle. ${ }^{83,85}$ Lesion volume increases even up to 300 seconds in duration of energy delivery. A depth of $8.1 \pm 1.5$ $\mathrm{mm}$ may be achieved at 300 seconds and 85 degrees $\mathrm{C}$.

Ultrasound energy may also be applied to the atrium and ventricle. It is being used for ablation of focal atrial fibrillation and for atrial tachycardias. It may be possible to combine ultrasound imaging and ablation in the same device. ${ }^{86-87}$

In summary, ultrasound ablation is in the early stages of experimental and clinical applications. Ultrasound ablation may be particularly well suited for the ablation of focal atrial fibrillation and ventricular tachycardia. It may be possible to combine imaging and ablation.

\section{SUMMARY}

Modified radiofrequency energy, cryoablation, microwave, laser, and ultrasound technologies may demonstrate significant advantages over conventional ablation. These energy sources may permit the creation of larger and longer lesions for the treatment of ventricular tachycardia and atrial arrhythmias. 
Matching the Energy Source to the Clinical Need / 93

\section{REFERENCES}

1. Bergau D, Brucker G, Saul J. Porous metal tipped catheter produces larger radiofrequency lesions through tip cooling [Abstract]. Circulation 1993; 88:I164.

2. Calkins H, Prystowsky E, Carlson M, 1. Temperature monitoring during radiofrequency catheter ablation procedures during closed loop controls. Circulation 1994; 90:1279-1286.

3. Calkins $\mathrm{H}, \mathrm{s} \mathrm{H} \mathrm{W}, \mathrm{JM} \mathrm{E}$, et al. Safety and efficacy of catheter ablation of ventricular tachycardia using the cooled ablation system: Final report. PACE $1998 ; 12: 842$.

4. Dorwath U, Fiek M, Remp T, al. e. Radiofrequency catheter ablation using cooled electrodes: comparison of different technologies. Circulation 1998; 98:I436.

5. Groeneveld P, Haugh C, Estes N, et al. Panel electrode "pigtail" catheter using flexible electrically conductive material: a new design for increasing radiofrequency ablation lesion size [Abstract]. PACE 1993; 16:923.

6. Langberg $\mathrm{J}$, Wonnell $\mathrm{T}$, Chin $\mathrm{M}$, et al. Catheter ablation of the atrioventricular junction using a helical microwave antenna: a novel means of coupling energy to the endocardium. PACE 1991; 14:2105-2113.

7. Langberg J, Gallaher M, Strickberger S. Temperature-guided radiofrequency catheter with very large distet allectrodes. Circulation 1993; 88:245-249.

8. Nakagawa $\mathrm{H}$, Yamanashi $\mathrm{W}$, Pitha $\mathrm{J}$, et al. Comparison of in vivo tissue temperature profile and lesion geometry for radiofrequency ablation with a saline-irrigated electrode versus temperature control in a canine thigh muscle preparation. Circulation 1995; 91:2264-2291.

9. Petersen $\mathrm{H}$, Chen $\mathrm{X}$, Pietersen $\mathrm{A}$, et al. Temperature-controlled irrigated tip radiofrequency catheter ablation: comparison of in vivo an din vitro lesion dimensions for standard catheter and irrigated tip catheter with minim al infusion rate. J Cardiovasc Electrophysiol 1998; 8:409-414.

10. Ruffy R, Imran M, Santel D, et al. Radiofrequency delivery through a cooled catheter tip allows the creation of larger endomyocardial lesions in the ovine heart. J Cardiovasc Electrophysiol 1995; 6:1089-96.

11. Satake $\mathrm{S}$, Ohira $\mathrm{H}$, Okishige $\mathrm{K}$, et al. Temperature-guided radiofrequency ablation using a new catheter electrode of $12 \mathrm{~F}$ gold tip [Abstract]. Circulation 1993; 88:I-62.

12. Simmons W, Mackey S, He D, et al. Comparison of maximum myocardial lesion depth using radio-frequency energy delivered with a gold or platinum electrode [Abstract]. Circulation 1994; 90:I-270.

13. Skrumeda L, Mehra R. Comparison of standard and irrigated radiofrequency ablation in the canine ventricle. J Cardiovasc Electrophysiol 1998; 9:1196-1205.

14. Langberg J, Lee M, Chin M, et al. Radiofrequency catheter ablation: the effect of electrode size on lesion volume in vivo. PACE 1990; 13:1242-1248.

15. Mittleman R, Huang S, DeGuzman W, et al. Use of the saline infusion electrode catheter for improved energy delivery and increased lesion size in radiofrequency catheter ablation. PACE 1995; 18:1022-1027. 
16. Pires L, Huang $\mathrm{S}$, Lin $\mathrm{J}$, et al. Comparison of radiofrequency (RF) versus microwave (MW) energy catheter ablation of the bovine ventricular myocardium. PACE 1994; 17:782.

17. Lustgarten DL, Keane D, Ruskin J. Cryothermal ablation: mechanism of tissue injury and current experience in the treatment of tachyarrhythmias. Prog in Cardiovasc Dis 1999; 41:481-498.

18. Klein G, Sealy W, Pritchett E, et al. Cryosurgical ablation of the atrioventricular node His bundle: long term follow-up and properties of the junctional pacemaker. Circulation 1980; 61:8-15.

19. Dubuc M, Friedman P, Roy D, Thibault B, MTalajic. Reversible electrophysiologic effects using ice mapping with a cryoablation catheter. PACE 1997; 20:1203.

20. Gessman L, Agarwa J, T TE, RH Helfant. Localization and mechanism of ventricular tachycardia by ice mapping 1 week after the onset of myocardial infarctionin dogs. Circulation 1983; 68:657-666.

21. Okishige K, Stanhope W, G GC, et al. Feasibility of catheter cryoablation of epicardial ventricular tachycardia [Abstract]. PACE 1993; 16:923.

22. Gillette $\mathrm{P}$, Swindle $\mathrm{M}$, Thompson $\mathrm{R}$, Case $\mathrm{C}$. Transvenous cryoablation of the bundle of His. PACE 1991; 14:504-510.

23. Gill W, Fraser J, Carter D. Repeated freeze-thaw cycles in cryosurgery. Nature 1968; 219:410-413.

24. Markovitz L, Frame L, Josphson M, et al. Cardiac cryolesions factors affecting their size and a means of monitoring their formation. Ann Thorac Surg 1988; 46:531-535.

25. Gallagher J, Sealy W, W WA, et al. Cryo-surgical ablation of accessory atrioventricular connections: a method for correction of the pre-excitation syndrome. Circulation 1977; 55:471-478.

26. Harrison L, Gallagher J, Kasell J, et al. Cryosurgical ablation of the AV nodeHis bundle: a new method of producing AV block. Circulation 1977; 55:463470.

27. Fujino H, Thompson R, PG PG, et al. Histologic study of chronic catheter cryoablation of the atrioventricular conduction in swine. Am Heart J 1993; 125:1632-1637.

28. Holman W, Hakel D, Lease J, et al. Cryo-surgical ablation of the atrioventricular nodal reentry: histologic localization of the proximal common pathway. Circulation 1988; 77:1356-1363.

29. Bredikis J, Bredikis A. Cryosurgical ablation of left parietal wall accessory atrioventricular connections through the coronary sinus without the use of extracorporeal circulation. J Thorac Cardiovasc Surg 1985; 90:199-205.

30. Wang P, Aronovitz M, Schoen F, et al. Catheter cryoablation under the mitral annulus: a new method of accessory pathway ablation [Abstract]. J Am Coll Cardiol 1993; 21:357A.

31. Caceres J, Werner P, Jazayeri M, et al. Efficacy of cryosurgery alone for refractory monomorphic sustained ventricular tachycardia due to inferior wall infarction. J Am Coll Cardiol 1988; 11:1254.

32. Thibault B, Villemaire C, MTalajic, et al. Catheter cryoablation in a more effective and potentially safer method to create atrial conduction block: Comparison with radiofrequency ablation. PACE 1998; 21:944.

33. Curtis A, Mansour M, Friedl S, et al. Modification of atrioventricular conduction using a combined laser-electrode catheter. PACE 1994; 17:337-348. 
34. Enders $\mathrm{S}$, Weber $\mathrm{H}$, Heinze $\mathrm{A}$, et al. Laser and radiofrequency catheter ablation of ventricular myocardium in dogs: a comparative test [Abstract]. PACE 1994; 17:782.

35. Haines D. Thermal ablation of perfused porcine left ventricle in vitro with the neodymium-YAG laser hot tip catheter system. PACE85. 1992; 15:979-985.

36. Hirao K, Suzuki K, Yamamoto N, et al. Transcatheter laser coagulation of canine atrial septum using a balloon-tipped endoscope: Anatomically guided catheter ablation under direct vision. PACE 1998; 21:849.

37. Isner J, Donaldson R, Deckelbaum L, et al. The excimer laser: gross, light microscopic and ultrastructural analysis of potential advantages for use in laser therapy of cardiovascular disease. J Am Coll Cardiol 1985; 6:1 102.

38. Lee B, Gottdiener J, Fletcher R, et al. Transcatheter ablation: comparison between laser photoablation and electrode shock ablation in the dog. Circulation6. 1985; 71.

39. Levine J, Merillat J, Stern M, et al. The cellular electrophysiologic changes induced by ablation: comparison between argon laser photoablation and highenergy electrical ablation. Circulation 1987; 76:217-225.

40. Littmann L, Svenson R, Brucker G, et al. Comparative study on the efficacy and safety of transcatheter radiofrequency ablation and contact neodymium-YAG laser photoablation of the left ventricular endocardium in dogs [Abstract]. PACE $1993 ; 16: 859$.

41. Mehta D, Bharati S, Lev M, Saksena S. Histopathological changes following laser ablation of a left-sided accessory pathway in a human. PACE 1994; 17:672-677.

42. Narula $\mathrm{O}$, Bharati S, Chan M, et al. Microtransection of the His bundle with laser radiation through a pervenous catheter: correlation of histologic and electrophysiologic data. Am J Cardiol 1984; 54:186-192.

43. Narula O, Boveja B, Cohen D, et al. Laser catheter-induced atrioventricular nodal delays and atrioventricular block in dogs: acute and chronic observations. J Am Coll Cardiol 1985; 5:259-267.

44. Obelienius V, Knepa A, Ambartzumian R, et al. Transvenous ablation of the atrioventricular conduction system by laser irradiation under endoscopic control. Lasers Surg Med 1985; 5:469-474.

45. Ohtake $\mathrm{H}$, Misaki $\mathrm{T}$, Watanade $\mathrm{G}$, et al. Myocardial coagulation by intraoperative Nd:YAG laser ablation and its dependence on blood perfusion. PACE 1994; 17:1627-1631.

46. Pfeiffer D, Moosdor R, Svenson R, et al. Epicardial Neodynium:YAG laser photocoagulation of ventricular tachycardia without ventriculotomy in patients after myocardial infarction. Circulation 1996; 94:3221-3225.

47. Rosenthet al, Montarello J, Bucknall C, et al. His bundle ablation with the laser thermal probe ("hot Tip"): a feasibility study. PACE 1989; 12:812-822.

48. Saksena S. Catheter ablation of tachycardia with laser energy: issues and answers. PACE 1989; 196-203:12.

49. Saksena S, Gielchinsky I. Argon laser ablation of modification of the atrioventricular conduction system in refractory supraventricular tachycardia. Am J Cardiol 1990; 66:767-770.

50. Schuger S, McMath L, Abrams G, et al. Long-term effects of percutaneous laser balloon ablation from the canine coronary sinus. Circulation 1992; 86:947-954. 
96 / Critical Reviews Vol. CR75

51. Svenson R, Littmann L, Splinter R, et al. Application of lasers for arrhythmia ablation. In: Jalife DZaJ, ed. Cardiac electrophysiology: from cell to bedside. Philadelphia:: WB Saunders, 1990.

52. Vincent G, Fox J, Knowlton K, Dixon J. Catheter-directed neodymium:YAG laser injury of the left ventricle for arrhythmia ablation: dosimetry and hemodynamic, hematologic, and electrophysiologic effects. Lasers Surg Med 1989; 9:446-453.

53. Weber H, Enders S, Keiditisch E. Percutaneous Nd:YAG laser coagulation of ventricular myocardium in dogs using a speciet allectrode laser catheter. PACE $1989 ; 1210 .: 899-910$.

54. Weber H, Heinze A. Laser catheter ablation of atrial flutter and of atrioventricular nodal reentrant tachycardia in a single session. Eur Heart J 1994; 15:1147-1149.

55. Weber $\mathrm{H}$, Kaltenbrunner $\mathrm{W}, \mathrm{A} \mathrm{AH}$, et al. Laser catheter ablation for patients with atrioventricular nodal reentrant tachycardia [Abstract]. PACE 1994; $17: 815$.

56. Weber H, Heinze A, Enders, et al. Catheter-directed laser coagulation of atrial myocardium in dogs. Eur Heart J 1994; 15:971-980.

57. Weber H, Heinze A, Enders S, et al. Mapping guided laser catheter ablation of the atrioventricular conduction in dogs. PACE 1996.; 19:176-187.

58. Weber H, Heinze A, Enders S, et al. Laser versus radiofrequency catheter ablation of ventricular myocardium in dogs: A comparative test.. Cardiology 1997; 88:346-352.

59. Zheng S, Kloner R, Whittaker P. Ablation and coagulation of myocardial tissue by means of a pulsed holmium:YAG laser. Am Heart J 1993; 126:1474-1477.

60. Coggins $\mathrm{D}$, Chin $\mathrm{M}$, Wonnell $\mathrm{T}$, et al. Efficacy of microwave energy for ventricular ablation [Abstract]. PACE 1991; 14::703.

61. Cohen $\mathrm{T}$, Coggins $\mathrm{D}$, Chin $\mathrm{M}$, et al. Microwave ablation of ventricular myocardium: the effects of varying duration on lesion volume [Abstract]. Circulation 1991:II-711.

62. Cohen T, $\operatorname{coggin} \mathrm{D}, \mathrm{MC} C$, et al. Microwave ablation of atrial myocardium: the effects of varying duration on lesion volume [Abstract]. Circulation 1992; 86:I784.

63. Gu Z, Rappaport C, Wang P, VanderBrink B. A 2 1/4-turn spiral antenna for catheter cardiac ablation. IEEE Trans Biomed Eng 1999; 46:1480-1483.

64. Haines D, Whayne J. What is the radial temperature profile achieved during microwave catheter ablation with a helical cord antenna in canine myocardium? J Am Coll Cardiol 1992; 19:99A.

65. Haugh C, Davidson E, Estes N, et al. Pulsing microwave energy: a method to create more uniform temperature gradients. J Int Cardiac Electrophys 1997; 1:57-65.

66. Liem L, Mean R, Shenasa M, et al. In vitro and in vivo results of transcatheter microwave ablation using forward-firing tip antenna design. PACE 1996; 19:2004-2006.

67. Mazzola F, Huang S, Lin J, al. e. Determinants of lesion size using a 4millimeter split-tip antenna electrode for microwave catheter ablation. PACE 1994; 17:814.

68. Rappaport C, Gu Z, Wang P. Wide-aperature microwave catheter-based cardiac ablation. Prog Electromagn Res Symp Dig 1997:465. 
69. Rho $\mathrm{T}$, Ito $\mathrm{M}$, Pride $\mathrm{H}$, et al. Microwave ablation of canine atrial tachycardia induced by aconitine. Am Heart J 1995; 129:1021-1025.

70. Ruder M, Mead R, Baron K, Radin M, Higgins S. Microwave ablation: in vivo data. PACE 1994; 17:781.

71. Shetty S, Ishii T, Krum D, et al. Microwave applicator design for cardiac tissue ablations. J Microwave Power and Electromag Energy 1996; 31.:59-66.

72. Thomas S, Clout R, Deery C, et al. Microwave ablation of myocardial tissue: the effect of element design, tissue coupling, blood flow, power, and duration of exposure on lesion size. J Cardiovasc Electrophysiol 1999; 10:72-78.

73. Wang P, Schoen F, Aronovitz M, et al. Microwave catheter ablation under the mitral annulus: a new method of accessory pathway ablation [Abstract]. PACE 1993.; 16:866.

74. Wang P, Ahmad A, Lenihan T, et al. Developing and testing a feedback control system for microwave ablation: in vitro and in vivo results [Abstract]. PACE 1994; 17:782.

75. Wang $\mathrm{P}$, Gadhoke $\mathrm{A}$, Schoen $\mathrm{F}$, et al. Microwave catheter ablation via the coronary sinus: the need for power and temperature regulation [Abstract]. PACE 1994; 17:813.

76. Whayne J, Nath S, Haines D. The effect of antenna design and microwave frequency on tissue temperature profiles during microwave catheter ablation in vitro [Abstract]. Circulation 1992; 86:I-192.

77. Whayne J, Nath S, Haines D. Microwave catheter ablation of myocardium in vitro: assessment of the characteristics of tissue heating and injury. Circulation 1994; 89:2390-2395.

78. Wonnell T, Stauffer P, Langberg J. Evaluation of microwave and radiofrequency catheter ablation in a myocardium-equivalent phantom mode. IEEE Trans Biomed Eng 1992; 39:1086-1095.

79. Yang X, Watanabe I, Kojima T, et al. Microwave ablation of the atrioventricular junction in vivo and ventricular myocardium in vitro and in vivo. Jpn Heart $\mathrm{J}$ $1994 ; 34: 175-191$.

80. Jumrussirikul $P$, Chen $J$, Jenkins $M$, et al. Prospective comparison of temperature guided microwave and radiofrequency catheter ablation in the swine heart. PACE 1998; 21:1364-1374.

81. Spitzer S, Richter P, Knaut M, Schuler S. Treatment of atrial fibrillation in open heart surgery- the potential role of microwave energy. Thorac Cardiovasc Surg $1999 ; 47: 374-378$.

82. Knaut M, Spitzer S, Karolyi L, et al. Intraoperative microwave ablation for curative treatment of atrial fibrillation in open heart surgery- the MICRO-STAF and MICRO-PASS pilot trial. Thorac Cardiovasc Surg 1999; 47:379-384.

83. He D, Zimmer J, Hynynen K, et al. Preliminary results using ultrasound energy for ablation ofthe ventricular myocardium in dogs. Am J Cardiol 1994; 73:102931 .

84. Ohkubo T, Okishige K, Goseki Y, et al. Experimental study of catheter ablation using ultrasound energy in canine and porcine hearts. Jpn Heart J 1998; 39:399409.

85. Zimmer J, Hynynen $\mathrm{K}, \mathrm{He} \mathrm{D}$, et al. The feasibility of using ultrasound for cardiac ablation. IEEE Trans Biomed Eng 1995; 42: 891-7.

86. Packer D, Seward J, Chan R, et al. The utility of a new integrated high resolution intracardiac ultrasound/ablation system in a canine model [Abstract]. J Am Coll Cardiol 1995:353. 
98 / Critical Reviews Vol. CR75

87. Packer D, Chan R, Johnson S, et al. Ultrasound cardioscopy: initial experience with a new high resolution combined intracardiac ultrasound/ablation system. PACE 1994; 17:863. 